\title{
Evidence-Based Medicine and Healthcare Quality in the Context of Information Failure: The Case of the UK Fertility Sector
}

\author{
Minyan Zhu' ${ }^{1}$ (1)
}

Accepted: 21 June 2021 / Published online: 14 August 2021

(c) The Author(s) 2021

\begin{abstract}
Economic incentives in the context of a particular type of market failure-asymmetric information (which takes place when quality information relating to treatment is not available to patients before purchasing the treatment)—are highly relevant to the understanding of the lack of clinics' incentives to disclose reliable evidence (relating to treatment quality) in the practice of evidence-based medicine. Based on the case study of the UK in vitro fertilisation (IVF) sector, I show that inadequate quality provision (relating to treatment effectiveness and safety) can be associated with a lack of voluntary disclosure of reliable evidence in the practice of evidence-based medicine. In the absence of sufficient economic incentives on clinics to voluntarily acquire and disclose evidence, I discuss the rationale for legislation requiring mandatory evidence disclosure as a possible mechanism to facilitate the acquisition and revelation of evidence. I do so by drawing evidence from the economic literature relating to the impact of such legislation on firms' quality improvement. Practical implications for implementation are discussed (and illustrated with examples in the context of the UK IVF sector) with the purpose to facilitate the role of regulators in setting the standards for evidence disclosure to improve interpretability of such evidence, together with the role of patients in engaging with clinics and verifying such evidence to improve its reliability and, ultimately, quality of care.
\end{abstract}

\section{Key Points for Decision Makers}

The observation of a lack of voluntary quality disclosure can reflect suboptimal quality standards in healthcare.

Legislation requiring mandatory disclosure relating to treatment quality could be a non-market solution to the problem of inadequate quality standards in some segments of the healthcare sector where patients are responsive to such disclosure.

Care must be taken when designing such measures to avoid adverse incentives.

The role of patients in verifying and improving the accountability of disclosure should be promoted, especially with the increasing availability of digital platforms for quality review and information sharing.

On 5 January 2021, the author submitted a response to a public consultation initiated by the Competition and Markets Authority (CMA draft guidance for fertility clinics on consumer law: public consultation) based on some of the content in this paper.

Minyan Zhu

minyan.zhu@ reading.ac.uk

1 Department of Economics, University of Reading, Whiteknights Campus, Reading RG6 6EL, UK

\section{Introduction}

The role of evidence-based medicine (EBM) in modern medical professions remains controversial. Growing concerns relating to the quality of evidence along with growing practices of EBM (for example, Djulbegovic and Guyatt [1] summarised the progress in EBM during the last quarter century) raise a valid question as to whether the practice of EBM ultimately improves the quality of patient care (see, for example, a recent debate by Djulbegovic et al. [2,3] and Mondoux and Shojania [4]). This paper aims to provide an economic perspective when evaluating the role of EBM in delivering treatment quality. I highlight that economic incentives in the context of a particular type of market failureasymmetric information (which takes place when information relating to treatment quality is not available to patients before purchasing the treatment) - are highly relevant to the observation and understanding of the lack of clinics' disclosure of reliable evidence (relating to treatment quality) in the practice of EBM.

A market with low transparency of pre-purchase quality information available to buyers may discourage high-quality sellers from serving in this market. This is because the presence of low-quality sellers (taking the advantage of pooling with high-quality sellers) adversely affects uninformed buyers' perception of the 'average' quality for which they are 
or would be willing to pay. The ultimate result could be that there are a large number of low-quality sellers who have the incentive to withhold evidence/information relating to their own quality; in other words, low-quality provision associated with a lack of reliable evidence.

In the paper, the above and related economic incentives are illustrated in detail based on a case study of the UK fertility sector. I focus on the UK fertility sector because there are growing concerns relating to the observation that certain treatments, especially add-on treatments, ${ }^{1}$ in the sector are not always based on reliable evidence (see, for example, discussions by Heneghan et al. [5]). Concerned that certain in vitro fertilisation (IVF) clinic practices may be preventing or inhibiting patients from making informed choices, the Competition and Markets Authority (CMA), the UK's primary competition and consumer authority, published in November 2020 a draft guidance [6] for UK fertility clinics on consumer law with the purpose of helping fertility clinics understand and comply with their existing obligations under consumer law. At the time of writing, the CMA has not yet ruled out possible law enforcement actions against fertility clinics. The case therefore allows us to better understand possible reasons for the lack of reliable evidence in practice (Sects. 2 and 3) and possible ways to address it (Sect. 4).

Following Lambert [7], I consider EBM as "a set of techniques and practices squarely to the deployment of statistical measurements of outcome derived from population research". ${ }^{2}$ For the purpose of the paper (relating to quality incentives and outcomes), evidence when referred to as EBM is used to specifically focus on measured quality outcomes relating to treatment effectiveness and safety.

\section{A Review of Economic Evidence Relating to Quality Provision and Voluntary Quality Disclosure in the Context of Asymmetric Information}

As consumers, we often have to purchase products/services without necessarily having the information to judge their quality prior to purchase. Examples would be healthcare services or durable goods. Sellers may know the quality of the item they sell but it may be in their interest to withhold that

\footnotetext{
${ }^{1}$ Interventions offered in addition to standard IVF with the purpose to improve fertility outcomes.

2 As discussed by Djulbegovic and Guyatt [1], central to the epistemology of EBM is that what is justifiable or reasonable to believe depends on the trustworthiness of the evidence, and the extent to which we believe that evidence is determined by credible processes. Whereas it is not the primary purpose of this paper to assess the hierarchy of different types of evidence, the importance of quality and standards of evidence is discussed later in the paper (Sect. 4.2).
}

information. It is a well-established principle of economics that such markets associated with the market failure of asymmetric information (e.g. sellers have more information than buyers relating to quality), could suffer from the consequence of low-quality provision $[8,9]$. This is explained as follows using the example of healthcare clinics.

Patients do not know the quality of a treatment provided by a clinic before they undergo the treatment. They have a general idea about the expected quality (such as the average success rate) of the clinic as well as that of the sector. Based on such an expectation, they will decide how much they are willing to pay for such a perceived 'average' treatment. If we have a lot of low-quality clinics providing treatments with relatively low success rates, it will lower the patients' expectation of success rates and therefore their willingness to pay. If patients' willingness to pay is sufficiently lowered, high-quality clinics that incur more costs and investments to provide more successful treatments may decide not to provide their service in this market as the expected price is not high enough to cover their costs. Therefore, high-quality clinics are driven out of the market by the presence of a large number of low-quality clinics in the market who find it in their interest to hide quality. This results in lower average quality provision associated with a lack of quality-related evidence available to patients.

The above simplified illustration of an Akerlof-type of market failure explains intuitively why quality is likely to be underprovided in markets with asymmetric information. However the scenario described above is not representative of the real-world cases where buyers do not know the average quality of the goods/services ex ante and they may not even be able to observe or assess the quality ex post. Indeed, there is a large body of literature focusing on a specific type of goods whose quality cannot be evaluated in normal use. ${ }^{3}$ In particular, consider an expert (e.g. a doctor) who knows more about the type of good or service the buyer (e.g. the patient) needs than the buyer themselves. ${ }^{4}$ The expert seller is able to identify the treatment that fits a buyer's need best by performing a diagnosis (hence this type of market is also referred to as treatment and diagnosis markets). They can then provide the right quality and charge for it, or they

\footnotetext{
${ }^{3}$ Referred to as credence goods by Darby and Karni [10].

4 There is also another strand of literature looking at another type of credence goods where credence attributes are not correlated to enduse attributes. For instance, consumer goods are differentiated by process-attributes, e.g. organically produced food, as well as by use attributes, e.g. taste. The asymmetric information problem exists here as consumers cannot verify process-attribute claims, even after lengthy inspection or consumption of the good, whereas sellers possess such information. For this type of goods, success of the service is, by definition, not observable. Roe and Sheldon [11] for instance, argue how the use of 'self-labelling' could be a possible solution to mitigate the problem of asymmetric information.
} 
can exploit the informational asymmetry by defrauding the buyer. The literature (see comprehensive reviews provided by Dulleck and Kerschbamer [12] and Balafoutas and Kerschbamer [13]) establishes that dishonest seller behaviour can arise in several dimensions (rather than just the under provision of quality mentioned above), including (1) buyers being overcharged for the actual treatment they receive but cannot observe; (2) buyers being overtreated with unnecessary treatment, which buyers do not know if they need; and (3) buyers being undertreated with an inadequate treatment (the underprovision of quality mentioned above), the outcome of which buyers cannot observe or verify to hold the seller accountable. ${ }^{5}$

In addition, diagnoses are often imprecise and require a certain amount of effort invested by the expert (with healthcare services being a prime example of such a situation). Diagnosis effort is often not observable to the buyers. These facts could further worsen the problem of asymmetric information illustrated here. For instance, how can the expert be induced to perform the costly but unobservable diagnosis, and how can the expert be induced to reveal the diagnosis outcome truthfully?

In the healthcare setting, it is clear that to assess the quality of the treatment, patients need to have information regarding what treatment they need, what treatment they receive, and the treatment outcome. The above economic evidence indicates clinics have a clear lack of incentives to acquire and disclose such information.

Incentives for quality disclosure require further explanation. Consider a seller with private (but verifiable) information about the quality of their product. Economic theory predicts sellers do have incentives to voluntarily disclose such quality information, even if it is unfavourable information, if certain conditions are satisfied [17-19]. The intuition behind this is as follows.

For sellers, voluntary disclosure has the benefit of correcting buyers' perception of the product quality. If the seller does not disclose their private information about the product quality, the most they can charge is the value of an average-quality product. Thus, if the actual value of the product is higher than that of an average product, the seller

\footnotetext{
${ }^{5}$ Earlier studies show if buyers can observe/verify the quality ex post, some market mechanisms such as warranties [8], reputation, or repeated purchases $[14,15]$ may work to mitigate the low-quality issue. In contrast, the evidence reviewed by Balafoutas and Kerschbamer [13] taken together, fails to find a significant or particularly systematic impact of reputation on dishonest behaviour in treatment and diagnoses markets, possibly relating to the fact that quality is difficult to verify ex post in these markets.

${ }^{6}$ Studies are still limited in this area. Balafoutas and Kerschbamer [13] provide a review, and Balafoutas et al. [16] provide some evidence, that diagnostic uncertainty further increases the possibilities of dishonest behaviour by sellers.
}

would choose to disclose quality. The consumers, in turn, revise downwards their estimate of the quality of products whose quality is not disclosed by sellers. This causes more types of sellers to disclose, and the process repeats itself until all types disclose ('unravelling'). It follows that all sellers (high- or low-quality type) will voluntarily disclose quality, implying that costly government-mandated disclosure is inefficient and unnecessary.

The above 'unravelling' should in principle resolve the quality problem associated with asymmetric information. However, a number of strong assumptions are required for the ideal result to hold. One could view those factors that violate the assumptions as forming a quality threshold. If firms' quality level (even though above average) is below the threshold, they may decide not to voluntarily disclose quality unilaterally. Such factors may be the cost of acquiring or verifying quality information $[17,20]$, or whether consumers understand or perceive nondisclosure as a signal of the lowest quality [21, 22], how many firms there are in the market $[23,24]$, how firms compete with each other [25] and how competitive they are at setting their prices [26].

To understand whether a lack of voluntary evidence disclosure is likely to occur in practice and how that is associated with clinics' incentives relating to quality improvement, I look at a case study of the UK IVF sector. I first document some stylised observations based on the reported results from interviews and a survey conducted by the CMA [27] and the sector regulator Human Fertilisation and Embryology Authority (HFEA) [28]. Based on the stylised observations, I then illustrate the economic evidence reviewed above in the context of the UK IVF sector to understand the practical implications of lack of evidence disclosure on treatment quality. I focus on two very important dimensions of quality, i.e. the effectiveness and safety of treatments, as they are confirmed to be the most important quality attributes of IVF treatment by the response data reported by the CMA [27] and HFEA [28].

\section{A Case Study: The UK In Vitro Fertilisation Sector}

Every year around 70,000 cycles of IVF treatment take place in the UK [29]. The UK fertility market is worth around $£ 320$ million annually and has enjoyed steady growth over recent years $[6,30]$. Treatment in the private sector continues to grow. The share of IVF cycles funded by the NHS has declined across most English regions over recent years, with $65 \%$ of treatment cycles in 2018 in England being selffunded [29]. I focus the following analysis on private fertility clinics that provide IVF treatment to self-funded patients. 


\subsection{Stylised Observations}

The stylised observations in the UK fertility sector are based on the reported results from the national patient survey data collected in 2018 by the HFEA [28] and findings reported in the CMA's research report [27] when developing the draft guidance [6] for fertility clinics and patients mentioned above. Further details relating to the two sources of information are explained in Appendix 1, with an overview of patient responses to treatment quality in Table 1 of the Appendix 1.

\subsubsection{Observation 1: Incomplete and Sometimes Misleading Evidence Disclosure of Success Rates}

UK IVF clinics often advertise the headline success rates by using the measure that gives them the highest success rate. With the revised code of conduct issued by the HFEA [31], the reporting of success rates has become more comprehensive. However, as reported by the CMA [27], a small group of respondents stressed the difficulties they experienced when comparing success rates for different clinics due to a perceived lack of consistency in how success rates were reported. Another small group questioned the accuracy of success rates, based on greater experience of IVF treatment and/or a more informed perspective on statistics. Many objected to clinics presenting success rates based on pregnancies, as respondents were more interested in those based on live births.

One prominent response relating to the information disclosure of success rates emerging from the survey conducted by the HFEA [28] is the lack of information on personalised chance of success. The CMA [27] confirms that many respondents reported that success rates of IVF treatment were generally discussed in generic rather than personalised terms. Although a few reported discussing their personal chance of success, most did not, and the specific basis for the individual discussions reported (i.e. whether test results, scans, age and previous history of IVF and any specific fertility issues) is unclear. For those with unsuccessful experiences, the HFEA [28] responses point out that overestimated personal success rates are misleading (see quoted responses in Figs. 1 and 2 in Appendix 1).

\subsubsection{Observation 2: Incomplete Evidence Disclosure of Effectiveness or Safety of Add-On Treatments and Fertility Drugs}

The CMA [27] recognises that there is a lack of consistency with respect to conveying information about the evidence for the effectiveness of add-on treatments to patients, that is, informing them there is little or no robust evidence, and of the risks where appropriate. Meanwhile, patient responses documented by both the CMA [27] and HFEA [28] indicate that some patients demand more evidence-based estimates of the effectiveness of certain treatments (see quoted responses in Fig. 3 in Appendix 1).

Respondents (interviewed by the CMA [27]) who were interested in what they described as 'medication-light IVF' treatment sometimes felt their choice was limited and that they had to work harder to find suitable clinics. It is worth pointing out that clinics' incentives are not typically aligned with those of the patients. If heavy use of drugs can increase the number of eggs retrieved, it means treatment is more likely to continue. In addition, the phenomenon of expensive fertility drugs in the UK provided by clinics that are often linked with dedicated distributors is consistently reported among respondents interviewed by the CMA [27]. High profit margins associated with these fertility drugs could drive overprescription of such drugs. The result is that some patients may end up being overprescribed with such drugs, incurring high costs, possible adverse effects or long-term health risks (imposed on the mother, children, or both).

\subsection{Incomplete Evidence Disclosure in the UK Fertility Sector May Well Reflect Inadequate Quality Provision}

If there were clinics providing distinctively high-quality treatments in this sector, there should be great incentives for them to unilaterally and voluntarily reveal more treatment evidence, such as personalised success rate, to demonstrate their distinctively high quality. Linking to the economic evidence discussed earlier, I provide a number of reasons for this.

First, patients in this sector are largely responsive to quality information. Treatment effectiveness of a given location is the top determining factor considered by patients when choosing a clinic, whereas cost as a determining factor is quite far down the list in comparison (confirmed both by the HFEA [28] and CMA [27]; also see Table 2 in Appendix 1). In fact, as some of the responses quoted above indicate (see Figs. 1, 2 and 3 in Appendix 1), patients indeed demand to know their personal chance of success as a measure of treatment quality. This is consistent with existing evidence provided by Bundorf et al. [32] that suggests patients are responsive to quality report cards when choosing among providers in the fertility sector in the US.

Second, cost associated with acquiring and verifying quality-related evidence is not prohibitively high. Whereas randomised clinical trials could be time-consuming, routinely collected data by clinics could also reveal useful information about the treatment quality at a given clinic. It may incur some cost to analyse such data to assess, at least to some extent, the effectiveness or safety of the existing treatments and drugs, but overall the cost of a more complete 
quality disclosure (than what is currently disclosed) is not prohibitively high. Based on patients' responses documented by the CMA [27] and HFEA [28], even evidence based on routinely collected data is not typically provided to inform patients of potential effectiveness or risk associated with treatments.

One may argue that, even if clinics are not directly disclosing evidence, they could indirectly signal high-quality services (especially if such evidence is difficult to verify), for instance through warranty, pricing, advertisement or research and development [33, 34]. A quick search of the UK IVF clinics' websites reveals that little to no information is available to indicate that these IVF clinics are investing competitively in R\&D to differentiate their treatments. The author is not aware of any clinics in the UK that provide any warranty related to treatment outcomes or safety. There is also very little evidence to suggest that price differences among clinics are signalling distinctive quality levels ${ }^{7}$.

Therefore, a plausible explanation for incomplete evidence disclosure observed in the sector is that it reflects a relatively low or inadequate level of quality provision in terms of treatment effectiveness and safety. Indeed, the reported live birth rate data strongly indicates there is great room for improvement in terms of treatment effectiveness, especially considering the relatively high cost associated with private IVF treatments in the UK. Note that for every 10 embryos transferred, on average in the UK in 2018, about 2.3 embryos survive and develop into live birth [29].

Given that clinics fail to disclose reliable evidence fully and voluntarily in practice, especially if the quality of treatment is not sufficiently high, a question that naturally arises is 'Could it be a possible mechanism to facilitate the acquisition and revelation of more evidence if clinics are required by law to disclose such evidence unilaterally, in the absence of sufficient economic incentives on clinics to voluntarily disclose such evidence?' I aim to address this question next.

In the CMA's draft guidance [6], various standards of mandatory information disclosure have been established for this sector. The information disclosure standards are primarily concerned about transparency, comparability and consistency of the information relating to clinics' treatment costs. The draft guidance makes a much less explicit requirement for fertility clinics to disclose quality-related information, including evidence on effectiveness and risk associated with add-on treatments.

\footnotetext{
${ }^{7}$ Further evidence to support this statement is available from the author based on price data collected from each clinic in central London.
}

\section{Legislating Mandatory Evidence Disclosure}

\subsection{A Review of Economic Evidence Relating to the Effect of Mandatory Quality Disclosure on Firms' Quality Provision}

Mandatory quality disclosure is extensively examined in the economics literature as a non-market solution to problems associated with quality provision in the context of asymmetric information. Theoretical evidence of the impact of mandatory quality disclosure on quality provision is not clear-cut and suggests that the impact depends on the reason for incomplete disclosure as mentioned earlier. For instance, when non-disclosure is innocent and due solely to disclosure costs, mandatory disclosure is socially excessive [35]. Mandatory disclosure of information, but not acquisition of information, may motivate sellers to reduce information acquisition [36, 37].

It should be noted studies in this body of theoretical literature typically maintain the assumption that firms' quality is given, overlooking the possibility that quality disclosure can incentivise firms to choose high-quality product. Therefore, the benefit of mandatory quality disclosure could be underestimated in the evidence mentioned above. Taking into account quality incentives, Fishman and Hagerty [21] show that firms' incentives to improve quality could be higher under the law, even if very few consumers understand the disclosure. However, limited attention of buyers means greater disclosures of multiple dimensions could reduce the average accuracy of buyers' perception and that a complex balance of considerations of discourse of different dimensions is needed [23].

There is fairly strong empirical evidence from a variety of markets, indicating that mandatory disclosure could improve quality standards (e.g. Mathios [38] provides evidence in the food sector, while Bennear and Olmstead [39] provide evidence relating to drinking-water suppliers). In the healthcare sector, consistent with the theoretical evidence mentioned above, the empirical evidence demonstrates that consumers have different receptiveness to mandatory quality reports [40-42], implying the effect on quality provision may vary depending on consumers' responsiveness.

Another potential benefit of mandatory disclosure that is less studied (theoretically or empirically) is the longerterm effects associated with better consumer selection and matching of products with more complete information [43], especially with the rapid development of information and communication technology (ICT) and digital platforms to dissipate information among consumers. Barriers to search or switch clinics could hinder patients from finding the bestquality clinic and make patients captive to a certain degree, creating little incentives on clinics with respect to exercising 
the amount of effort expected by the patient to deliver the individual outcome. By breaking down such barriers, quality disclosure may drive out low-quality clinics, encourage entry by high-quality competitors, or incentivise existing clinics to improve quality. Such an effect may be achieved with the presence of a proportion of consumers who are empowered by pre-purchase quality information to improve matching and quality selection, generating positive externality on consumers who ignore quality disclosure.

Illustrated in the case of the UK fertility sector, if quality provision is indeed a problem in the context of asymmetric information as established earlier, and considering patients are responsive to and engaging with evidence disclosure, legislation requiring mandatory evidence disclosure is likely to improve the standard of quality provision. In addition, quality information disclosure may help break down any barriers patients face to search and switch clinics (e.g. initial consultation fees typically cost around $£ 200$ in London, paid by patients to find a match; clinic locations as identified by the CMA [27] and Table 2 in Appendix 1).

However, the literature in economics suggests that inappropriate measures of mandatory information disclosure could create adverse incentives on the firms, resulting in not only no improvement in quality but even harm to consumers. Therefore, care must be taken when designing such measures. An extensive list of examples in the healthcare and education sector are reviewed by Dranove and Jin [44]. Based on the evidence presented in this body of literature, in the following I explain, in the context of the UK fertility sector, the implications of implementing mandatory evidence disclosure on the practice of EBM. In particular, I highlight the role of regulators in setting the standards of disclosed evidence to improve interpretability, and patients' role in engaging with clinics and verifying such evidence to improve accountability.

\section{The Implications of Implementing Mandatory Evidence Disclosure for the Practice of Evidence-Based Medicine in the UK Fertility Sector}

Mandatory disclosure may fail to achieve any desired impact on treatment quality if the evidence disclosed is very difficult for patients to interpret or if the information is simply irrelevant. Take success rate in the fertility sector as an example. The success rate for a female patient aged 30 years with male infertility factors may have little relevance to another female patient aged 40 years with a completely different infertility issue. How can the success rate inferred from a sample of patients be easily interpreted by and applicable to individual patients?
This is not an insurmountable problem. Each clinic has access to the treatment data routinely collected by the clinic. Such data can be used to form estimations of personalised success rates of IVF treatment. Example 1 in Appendix 2 illustrates in greater detail how this could be done based on an established statistical model adopted by NHS England for a different purpose (which is to compare risk-adjusted hospital-level mortality rates). I illustrate in the example how the relevant statistical model can be used to estimate with a certain degree of precision the expected rate of success of a given patient with certain characteristics, which can then be compared with the observed rate of success in the clinic for such patients.

Whatever quality measures are used, they are unlikely to be perfect. In the fertility sector, reported evidence depends on the characteristics of the patients (such as underlying causes of infertility, any pre-existing conditions, and age, etc.), as well as the performance of the clinic. Clinics can improve performance rating by strategically selling to the 'right' patients and refusing complex cases. Such adverse incentives are highlighted by Dranove et al. [45] in the empirical case of mandated 'cardiac surgery report cards' in the US. This stresses the importance of reporting the success rate adjusted for patient mix of a given clinic as a measure to help patients effectively review and verify clinics' performance. Example 2 in Appendix 2 illustrates in further detail how this could be achieved based on NHS's established practice of comparing and reporting risk-adjusted mortality rates (for different diagnoses) across hospitals.

To increase the reliability of the evidence disclosed by clinics, it is important that such evidence is verifiable, at least to some extent. Buyers' willingness to pay is influenced not only by the availability of the evidence but also by their perceived reliability of the available evidence. Even though value judgement is ultimately unavoidable when determining the reliability of evidence, in practice, developing standards/ practical guidelines to assist with the assessment of reliability of available evidence ${ }^{8}$ could allow less distorted elicitation of values and preferences about management options presented to the end users. Example 3 in Appendix 2 illustrates how data and methods for producing the evidence could be assessed in the case of IVF success rates to ensure the reliability of evidence to some extent.

Mandatory disclosure may fail to achieve any desired impact on treatment quality if a large number of patients decide not to engage with the disclosed evidence. In the

\footnotetext{
${ }^{8}$ For instance, the Grading of Recommendations Assessment, Development and Evaluation (GRADE) approach provides a framework for assessing the quality (or 'certainty') of the evidence [46]. Also see the review by Busse et al. [47] (Chapter 9) of other approaches and such practical guidelines applied in different European countries.
} 
UK fertility sector, for instance, HFEA survey evidence (see Table 3 in Appendix 1) indicates that patients make use of online information when searching for clinics and would like to be more engaged with clinics to improve treatment outcome.

Mandatory quality disclosure could lower the barriers to patients' pre-purchase search for clinics. The regulator could also play a more prominent role to encourage patients to review their experiences and advertise such an informationsharing platform to the public. Such platforms can also be used to facilitate independent quality (especially in relation to treatment effectiveness and safety) review based on patients' feedback. This will help patients to increase their chances of selecting good-quality clinics. Example 3 in Appendix 2 further illustrates this point. Unfortunately, not many patients in the selected sample documented by the CMA [27] and HFEA [28] (see Tables 2 and 3 in Appendix 1) are aware of the existing HFEA webpage that allows patients to review their experiences, provide ratings, and access success rates (but not personalised, or adjusted for patient mix) across clinics.

Since the quality of treatments is not only reflected in the dimension of effectiveness but also in the dimension of safety, mandatory disclosure may harm patients if clinics only focus on boosting the reported success rate at the expense of unreported long-term safety. This explains why regulators play a very important role in verifying the longterm safety of treatments and drugs. For instance, the sector regulator could prioritise resources to commission independent research into the understanding of the long-term risk of the commonly used fertility drugs/treatments facing both patients and children conceived as a result of the relevant IVF treatments by doing long-term follow-up studies with IVF patients/children.

Given the challenges mentioned above in implementing mandatory disclosure, a point worth discussing is whether there might be better alternatives. There are other possible institutional solutions discussed in the literature, especially relating to treatment and diagnosis markets (see a review by Balafoutas et al. [13]). One potential remedy extensively discussed is the use of liability clauses (by e.g. Fong et al. [48] and Dulleck et al. [49]) to mitigate the issue of underprovision of quality (and other adverse incentives mentioned in Sect. 2). Whereas it is in theory a potentially powerful mechanism, the implementation of liability rules in practice requires that the success of a service is not only observable by the patient but also verifiable. In many cases, the success of services cannot be easily observed or verified. For instance, in the IVF sector, success is in part random. Thus, a failing treatment is no perfect signal of undertreatment. The effectiveness of liability clauses therefore necessarily requires the disclosure of reliable evidence relating to treatment effectiveness and safety.
Even though liability clauses may be difficult to implement without quality disclosure, some studies dating back to 1963 (Arrow [9]) discuss the implications of the possibility that physicians have ethical obligations for the patients' welfare. If so, one should expect such ethical concerns to reduce the adverse effects on treatment quality arising from the informational asymmetry between patients and physicians.

There is some evidence from experiment laboratories to indicate that financial incentives are not the only motivating factor for physicians who may exhibit some degree of altruism and concerns for patients' needs (see, for example, evidence provided by Hennig-Schmidt et al. [50] and Hennig-Schmidt and Wiesen [51]) and that experts who have made a non-binding promise to a consumer are indeed less likely to engage in fraud [52]. However, given that the degree of ethical concerns for patients may well differ from one physician to another (see, for example, evidence provided by Godager and Wiesen [53]), ${ }^{9}$ the overall impact on seller behaviour remains unclear. ${ }^{10}$ In addition, the above observations in the IVF sector suggest that clinics as a collective organisation, as well as individual physicians, may not always have compatible incentives. For instance, IVF patients have a tendency to avoid regret and are therefore likely to be less sceptical about the effectiveness of add-on treatments (see patient quotes in Fig. 3 in Appendix 1). As a result, clinics as an institution may have little incentives to invest in diagnosis efforts to better understand (and ultimately improve) the effectiveness and safety of treatments. In this case, even though individual physicians (facing a lack of available evidence) may have ethical concerns for patient welfare, what they can do individually to improve the quality of care for patients is likely to be limited.

\footnotetext{
${ }^{9}$ Delfgaauw [54] points out that altruistic doctors are more likely to be self-selected to treat publicly funded patients as it is more rewarding for them. From this perspective, one might expect that the issue relating to quality standards attributed to asymmetric information may be mitigated by ethical concerns to a greater extent in the public health sector than in the private health sector. Kruse et al. [55] indeed provided some empirical evidence to suggest that the private (for-profit) hospital sector seems to react more strongly to (financial) incentives than public (not-for-profit) providers, even though a conclusive statement cannot be made from their systematic review as to whether a public or private healthcare sector provides better quality of care.

${ }^{10}$ For instance, Kerschbamer et al. [56] argue that with the presence of anti-social doctors, even if the treatment can be observed and verified by patients, fraudulent behaviour is still more likely to arise than what the theory (typically assuming the standard rational and profitmaximising sellers) predicts. Similarly, with the presence of prosocial doctors, even if the treatment cannot be observed or verified by patients, the outcome may be better than what the theory predicts. Fong et al. [48] and Liu [57] point out the possibility that the presence of altruistic and honest experts allows the opportunistic experts to make more profit.
} 


\section{Conclusions}

Using the UK IVF sector as a case study, and based on economic evidence, I illustrate, that inadequate quality provision in terms of treatment effectiveness and safety can be associated with a lack of reliable evidence. To address the issue of suboptimal quality associated with clinics failing to disclose reliable evidence fully and voluntarily, I then assess the rationale for possible legislative intervention of mandating evidence disclosure. The discussion of mandatory evidence disclosure is extended to demonstrate that care must be taken when designing such measures to avoid adverse incentives.

The discussions above do not go much beyond the economic principles that could be applied to the understanding and design of mandatory quality disclosure, and the illustrative examples in Appendix 2 cannot fully capture adverse incentives associated with misrepresentation of evidence in all cases or segments of the healthcare sector. Similarly any general framework/standards to assess the reliability of evidence are unlikely to completely capture the misrepresentation of evidence in all cases.

However there are reasons to be optimistic. Our observations in the context of the IVF sector in the UK point to the important potential for patients to improve quality provision. Thanks to the rapid development of information technology, patients have better access to online information than ever. Patients also have means to share experiences and learn about the service provision of different clinics using online platforms or social media. Therefore, there is still plenty of room to further engage patients with clinics' service provision and evidence disclosure. Therefore, in my opinion, patients' role in evidence disclosure, assessment and verification, with the purpose to improve healthcare quality in the context of information asymmetry, is to be better understood and more fully explored in the new digital era.

It is important to note that the conclusions drawn from this study should be applied with caution to other segments within the healthcare sector. For instance, other areas of the healthcare sector may be characterised by patients who are more (or less) engaged/responsive to reliable evidence. The nature of the treatment may also determine how straightforward it is to construct objective measures of treatment effectiveness and safety. In publicly funded healthcare sectors, the provision of treatment quality depends in part on the government's willingness to pay, which is influenced by various government budget constraints and other factors which are not considered in this study.

\section{Appendix 1: Regarding the Human Fertilisation and Embryology Authority and Competition and Markets Authority Data: Some Descriptive Statistics and Quoted Responses}

The stylised observations (Sect. 3) are based on results from the national patient survey data collected in 2018 by the sector regulator, Human Fertilisation and Embryology Authority (HFEA) [28], and findings from the Competition and Markets Authority's (CMA's) research report [27] based on patient interviews carried out when developing the draft

Table 1 HFEA survey responses regarding IVF treatment: success rates, risk and overall satisfaction

\begin{tabular}{|c|c|c|c|}
\hline & IVF patients & NHS funding & Privately funded \\
\hline Count & 815 & 646 & 664 \\
\hline Outcome with the current situation & $\begin{array}{l}\text { Successful: } 36 \% \\
\text { Unsuccessful: } 34 \% \\
\text { Other (e.g. first treatment; } \\
\text { prefer not to say): } 31 \%\end{array}$ & $\begin{array}{l}\text { Successful: } 38 \% \\
\text { Unsuccessful: } 32 \% \\
\text { Other (e.g. first treatment; } \\
\text { prefer not to say): } 30 \%\end{array}$ & $\begin{array}{l}\text { Successful: } 41 \% \\
\text { Unsuccessful: } 32 \% \\
\text { Other (e.g. first } \\
\text { treatment; prefer } \\
\text { not to say): } 27 \%\end{array}$ \\
\hline Success rate communicated clearly & $21 \%$ disagree & $22 \%$ disagree & $24 \%$ disagree \\
\hline $\begin{array}{l}\text { The health risks of treatment such as adverse effects clearly com- } \\
\text { municated }\end{array}$ & $21 \%$ disagree & $22 \%$ disagree & $27 \%$ disagree \\
\hline Treatment add-ons: have had at least one & $67 \%$ & $66 \%$ & $74 \%$ \\
\hline Treatment add-ons: understood evidence about the effectiveness & $62 \%$ satisfied & $60 \%$ satisfied & $66 \%$ satisfied \\
\hline $\begin{array}{l}\text { Treatment add-ons: understood evidence about risks and adverse } \\
\text { effects }\end{array}$ & $60 \%$ satisfied & $59 \%$ satisfied & $63 \%$ satisfied \\
\hline Overall satisfaction with the most recent treatment & $75 \%$ satisfied & $75 \%$ satisfied & $73 \%$ satisfied \\
\hline
\end{tabular}

Source: HFEA [28]

HFEA Human Fertilisation and Embryology Authority, IVF in vitro fertilisation 


\section{The lack of information on personalised chance of success}

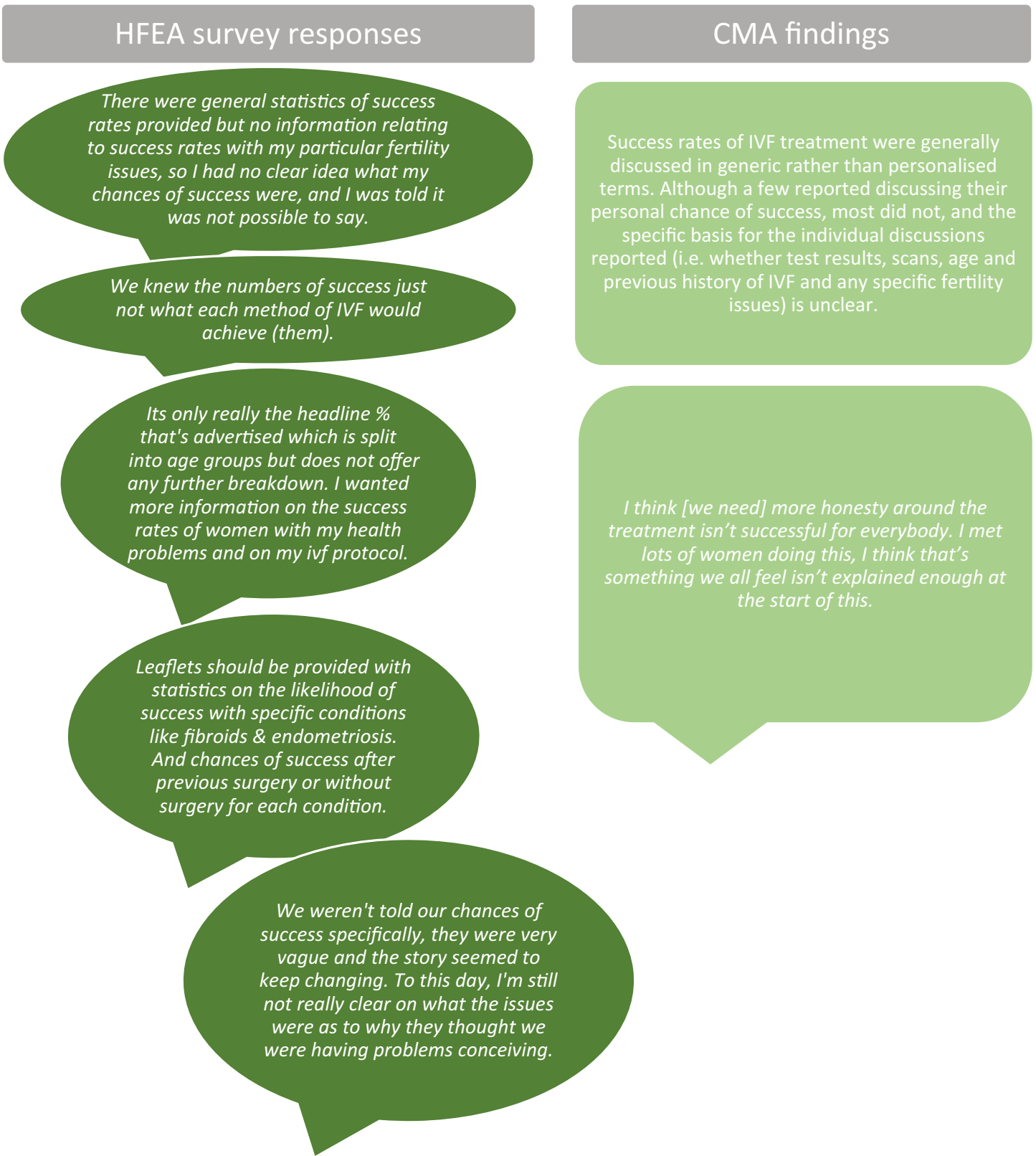

Fig. 1 Illustrating stylised observation 1 relating to incomplete information disclosure of personalised success rates. HFEA Human Fertilisation and Embryology Authority, CMA Competition and Markets Authority, IVF in vitro fertilisation. Source: CMA [27] and HFEA [28]

guidance for fertility clinics and patients in the UK in 2020 mentioned above [6]. ${ }^{11}$

CMA [27] is based on 50 paired in-depth telephone or video interviews with consumers who had bought IVF treatment in the past 2 years, and their partners. All respondents

\footnotetext{
11 Data availability statement: The HFEA survey results and CMA research findings are available for public access (see reference list). No new data were generated by the author.
}

paid for IVF treatment in the last 2 years and came from across the UK. The sample was further structured to ensure a wide range of experiences were captured, specifically in terms of different age groups, type of relationship, and whether patients paid for treatment in NHS or private clinics. With no direct access to the interview scripts, references to the CMA report [27] are based on the CMA's [27] reported research findings. 


\section{Overestimated success rates are misleading}

\section{HFEA survey responses}

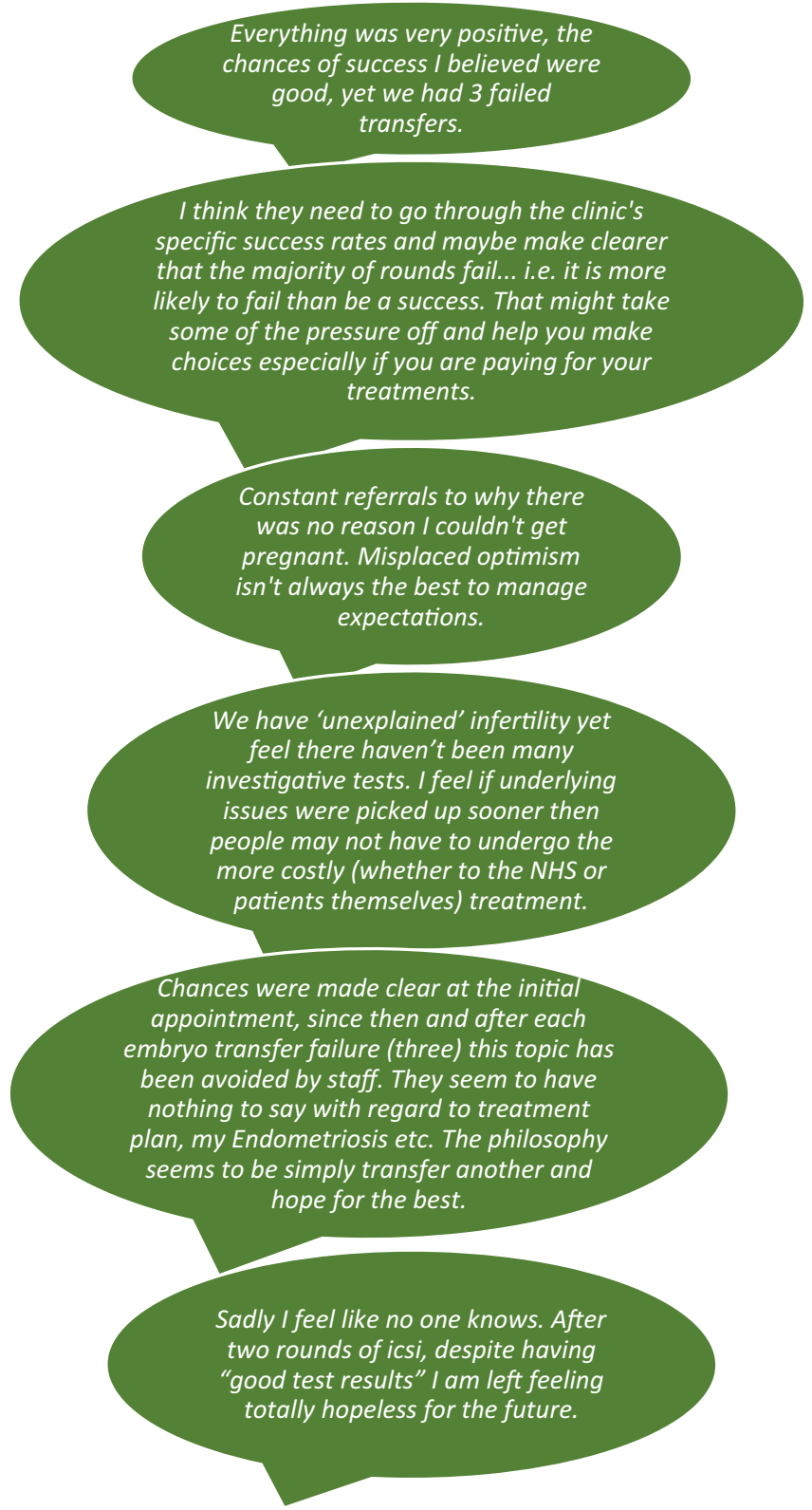

CMA findings

There are some cases where respondents had experienced repeated unsuccessful IVF treatments and were then given different treatments (typically add-ons that are not necessarily evidence-based) in the hope that one of them might work.

Fig. 2 Illustrating stylised observation 1 relating to overestimated success rates. HFEA Human Fertilisation and Embryology Authority, CMA Competition and Markets Authority, IVF in vitro fertilisation, ICSI intracytoplasmic sperm injection. Source: CMA [27] and HFEA [28] 


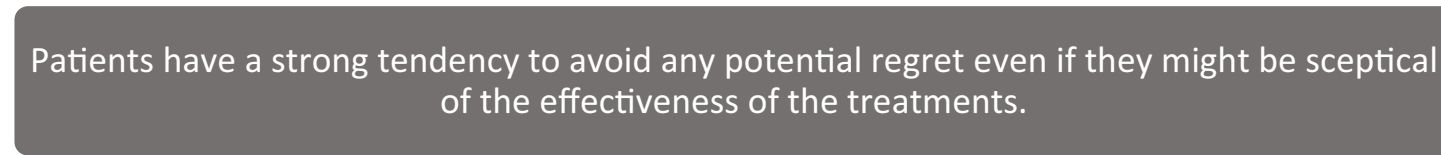

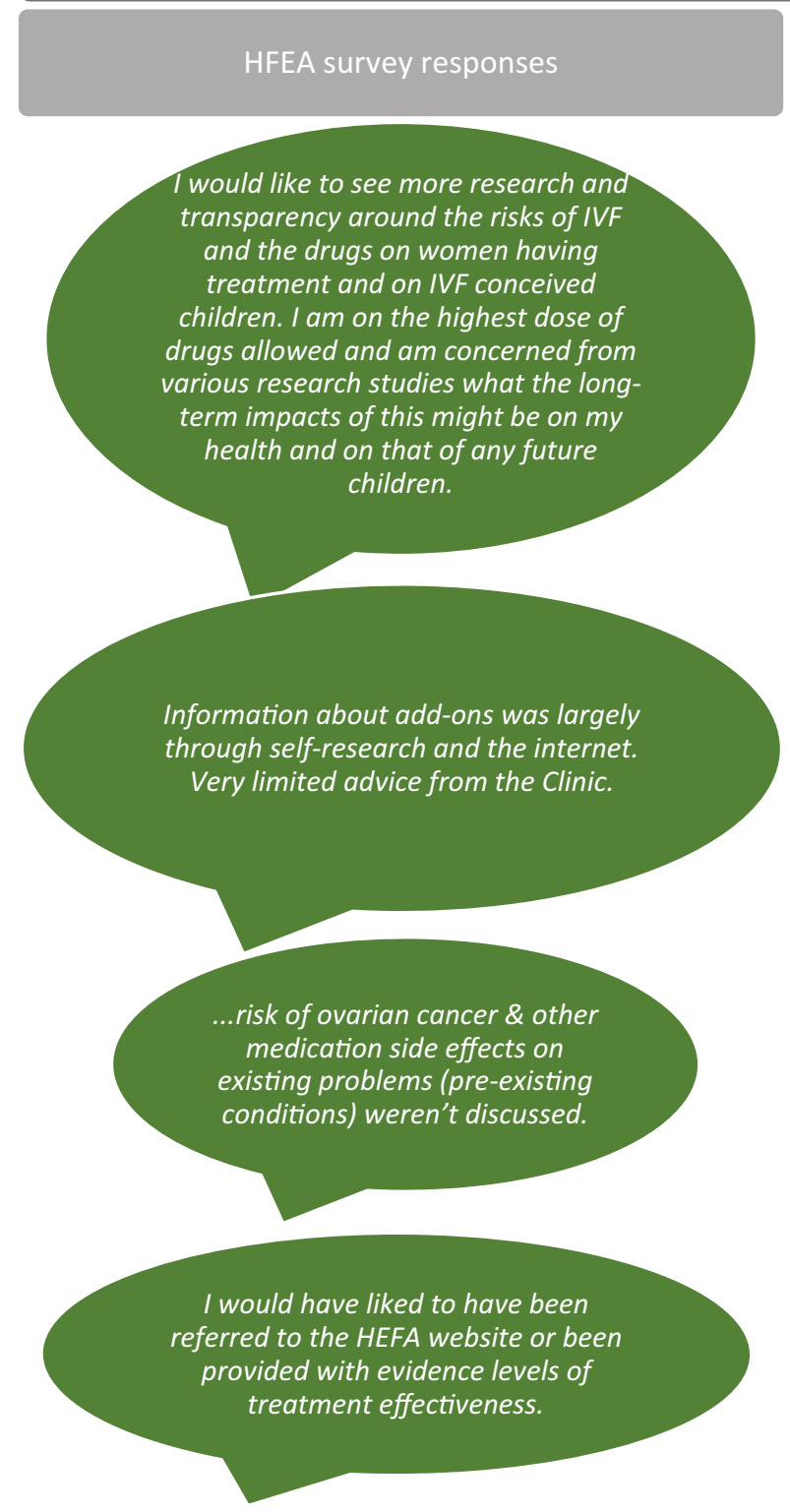

CMA findings

Many respondents did not recall that the risks of particular add-on treatments were discussed with them. The risk respondents recalled being discussed mainly concerned

those associated with medication, for

example, over-stimulation. Most did not recall other risks being discussed with them, for example, risks associated with particular tests or add-on treatments.

A small group of respondents felt that a lack of clinical evidence supporting the

effectiveness of add-ons did not necessarily mean that they were ineffective, particularly given their belief that effectiveness was

likely to vary between patients because of their different medical characteristics. As these respondents explained, since they already invested such large sums of money in this treatment, they wanted to try everything they could and avoid the fear of not doing so (even when sceptical).

I remember him [the consultant] saying, in terms of how beneficial it is, that it was difficult to say, but there's no disadvantages, so you might as well, just in case it does work. [Male participant]

I remember challenging him on that a little bit, and he said the jury's out, 50/50. He said it wouldn't harm it, and there was no reason not to. It was a small amount of money, which doesn't mean anything when you're trying to have a baby." [Female participant]

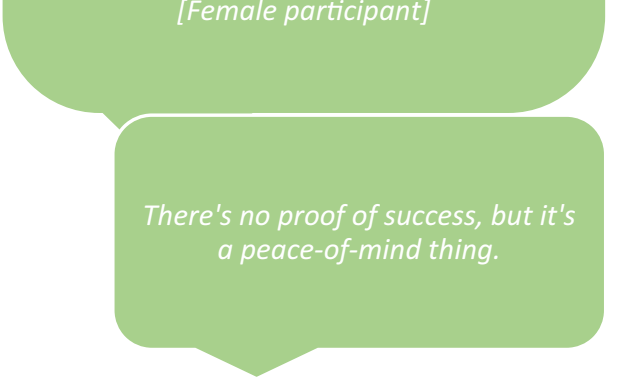

Fig. 3 Illustrating stylised observation 2 relating to the effectiveness or safety of add-on treatments and fertility drugs. HFEA Human Fertilisation and Embryology Authority, CMA Competition and Markets Authority, IVF in vitro fertilisation. Source: CMA [27] and HFEA [28] 
Table 2 Patients' reasons for choosing clinics: the HFEA responses

\begin{tabular}{|c|c|c|c|}
\hline & IVF patients & NHS funding & Privately funded \\
\hline Count & 815 & 646 & 664 \\
\hline $\begin{array}{l}\text { Six most important reasons you used a } \\
\text { particular clinic or clinics? }\end{array}$ & $\begin{array}{l}\text { Location/distance from home/ } \\
\text { work: } 55 \% \\
\text { Information about success rates: } \\
45 \% \\
\text { Referred there by GP: } 37 \% \\
\text { Good first impression of the clinic } \\
\text { and clinic staff: } 33 \% \\
\text { Treatment options offered: } 31 \% \\
\text { Referred there by a specialist con- } \\
\text { sultant: } 23 \% \\
\text { Cost: } 18 \% \\
\text { Clinic websites: } 19 \% \\
\text { Recommendation from family or } \\
\text { friends: } 18 \% \\
\text { Convenient opening hours/flexible } \\
\text { appointment times: } 17 \% \\
\text { The HFEA Choose a Fertility } \\
\text { Clinic website: } 17 \% \\
\text { Inspection ratings/reports: } 14 \% \\
\text { Events such as open evenings: } 11 \% \\
\text { Feedback on social networks, blogs } \\
\text { or forums: } 10 \% \\
\text { Other: } 8 \% \\
\text { Can't remember: } 0 \%\end{array}$ & $\begin{array}{l}\text { Location/distance from home/ } \\
\text { work: } 48 \% \\
\text { Information about success rates: } \\
39 \% \\
\text { Referred there by GP: } 47 \% \\
\text { Good first impression of the clinic } \\
\text { and clinic staff: } 30 \% \\
\text { Treatment options offered: } 27 \% \\
\text { Referred there by a specialist con- } \\
\text { sultant: } 25 \% \\
\text { Cost: } 17 \% \\
\text { Clinic websites: } 16 \% \\
\text { Recommendation from family or } \\
\text { friends: } 15 \% \\
\text { Convenient opening hours/flexible } \\
\text { appointment times: } 15 \% \\
\text { The HFEA Choose a Fertility } \\
\text { Clinic website: } 14 \% \\
\text { Inspection ratings/reports: } 15 \% \\
\text { Events such as open evenings: } 9 \% \\
\text { Feedback on social networks, blogs } \\
\text { or forums: } 11 \% \\
\text { Other: } 6 \% \\
\text { Can't remember: } 0 \%\end{array}$ & $\begin{array}{l}\text { Location/distance from home/ } \\
\text { work: } 56 \% \\
\text { Information about success } \\
\text { rates: } 47 \% \\
\text { Referred there by GP: } 23 \% \\
\text { Good first impression of the } \\
\text { clinic and clinic staff: } 41 \% \\
\text { Treatment options offered: } \\
34 \% \\
\text { Referred there by a specialist } \\
\text { consultant: } 19 \% \\
\text { Cost: } 23 \% \\
\text { Clinic websites: } 20 \% \\
\text { Recommendation from family } \\
\text { or friends: } 24 \% \\
\text { Convenient opening hours/ } \\
\text { flexible appointment times: } \\
20 \% \\
\text { The HFEA Choose a Fertility } \\
\text { Clinic website: } 19 \% \\
\text { Inspection ratings/reports: } \\
16 \% \\
\text { Events such as open eve- } \\
\text { nings: } 13 \% \\
\text { Feedback on social networks, } \\
\text { blogs or forums: } 14 \% \\
\text { Other: } 7 \% \\
\text { Can't remember: } 1 \%\end{array}$ \\
\hline
\end{tabular}

Source: HFEA [28]

HFEA Human Fertilisation and Embryology Authority, IVF in vitro fertilisation, GP General Practitioner

The HFEA survey involved responses from respondents who were either in the process of receiving fertility treatment or had been through the process in the last 5 years (i.e. with either a successful or an unsuccessful outcome). The total number of responses was 1017 patients or partners and the data were weighted to be representative by treatment type, age, region and partner status, according to statistics provided by the HFEA. With no access to the original survey data, the information presented here and in the main text is based on the survey results published by the HFEA [28]. I focus on the responses from the in vitro fertilisation (IVF) patients and provide an overview of their responses relevant to assessing the quality of IVF treatment in Table 1.

As mentioned above, the author does not have access to the original survey data and the above table 1 is compiled from the survey results published by the HFEA [28].Therefore, it is not possible to analyse the survey results directly focusing on the self-funded IVF patients $(60 \%$ of all IVF patients) as a subgroup. Instead, I look at the responses by IVF patients, patients funded by the NHS, and patients who are self-funded separately in the above table 1 .
The above survey results should be interpreted with caution. According to the HFEA [28], the outcome of treatment plays a role in determining overall satisfaction. Around 9 in $10(89 \%)$ of those who were successful in treatment in the past 2 years say they are satisfied overall, with no one saying that they were dissatisfied. For those who were unsuccessful, 3 in $10(30 \%)$ say that they are dissatisfied and considerably fewer (52\%) say they are satisfied. In the survey sample, 34\% of the IVF patients have had known unsuccessful outcomes. Note that the IVF failure rate is likely to be much higher than $34 \%$. For every 10 embryos transferred, on average in the UK in 2018 about 2.3 embryos survive and develop into live birth [29]. Therefore, the survey results in the above table 1 may be more optimistic than reality.

For the above reason, I have taken a closer look at responses to the open-ended questions in the HFEA survey. In particular, I have looked at patients' responses to the question "If you feel the chances of success were not clearly communicated, please add why you think that and what might make it clearer" and the question "If you have any comments or experiences you would like to share about 
Table 3 How patients search for initial information and clinics' engagement with patients: the HFEA responses

\begin{tabular}{|c|c|c|c|}
\hline & IVF patients & NHS funding & Privately funded \\
\hline Count & 815 & 646 & 664 \\
\hline $\begin{array}{l}\text { Searching initial information for } \\
\text { choosing clinics }\end{array}$ & $\begin{array}{l}\text { Search engines: } 62 \% \\
\text { Clinic websites: } 52 \% \\
\text { GP: } 46 \% \\
\text { HFEA website: } 44 \% \\
\text { Forums: } 35 \% \\
\text { Friends or family: } 25 \% \\
\text { Social network or online blog: } \\
32 \%\end{array}$ & $\begin{array}{l}\text { Search engines: } 59 \% \\
\text { Clinic websites: } 48 \% \\
\text { GP: } 52 \% \\
\text { HFEA website: } 40 \% \\
\text { Forums: } 33 \% \\
\text { Friends or family: } 22 \% \\
\text { Social network or online blog: } \\
32 \%\end{array}$ & $\begin{array}{l}\text { Search engines: } 57 \% \\
\text { Clinic websites: } 56 \% \\
\text { GP: } 37 \% \\
\text { HFEA website: } 45 \% \\
\text { Forums: } 34 \% \\
\text { Friends or family: } 28 \% \\
\text { Social network or online blog: } 33 \%\end{array}$ \\
\hline Felt listened to & $75 \%$ agree & $74 \%$ agree & $74 \%$ agree \\
\hline $\begin{array}{l}\text { Felt able to provide feedback at } \\
\text { any time }\end{array}$ & $65 \%$ agree & $65 \%$ agree & $67 \%$ agree \\
\hline Felt involved in treatment decision & $74 \%$ agree & $75 \%$ agree & $74 \%$ agree \\
\hline $\begin{array}{l}\text { Felt able to state concerns and } \\
\text { complaints at any time }\end{array}$ & $68 \%$ agree & $68 \%$ agree & $69 \%$ agree \\
\hline $\begin{array}{l}\text { To what extent are you able to } \\
\text { approach doctors/consultants for } \\
\text { support }\end{array}$ & $35 \%$ say a little or not at all & $36 \%$ say a little or not at all & $33 \%$ say a little or not at all \\
\hline $\begin{array}{l}\text { To what extent are you able to } \\
\text { approach the embryologist for } \\
\text { support }\end{array}$ & $45 \%$ say a little or not at all & $42 \%$ say a little or not at all & $45 \%$ say a little or not at all \\
\hline
\end{tabular}

Source: HFEA [28]

HFEA Human Fertilisation and Embryology Authority, IVF in vitro fertilisation, GP General Practitioner

treatment add-ons, please type in here". I also cross-check these responses with the findings from the CMA [28]. Figures 1, 2 and 3 below show the quoted responses to supplement the stylised observations in Sect. 3.

Tables 2 and 3 provide additional information relating to patients' reasons for choosing clinics, how they search for clinics and their perspective of engagement with clinics.

\section{Appendix 2: Illustrative Examples to Show How a Greater Extent of Evidence Discourse Relating to Success Rates in the Case of the UK Fertility Sector can be Achieved}

\section{Example $1^{12}$ An illustrative example of how personalised success rate can be disclosed \\ What data to collect?}

Individual clinics routinely collect data regarding their patients and the IVF treatment they receive. The regulators could set the standard definition with respect to the data sample to be selected and categorical variables to be used to

\footnotetext{
12 This example together with the next two examples are adapted based on the established practice of reporting Summary Hospitallevel Mortality Indicator (SHMI) relating to different diagnoses at NHS England. More details regarding this reporting practice can be accessed here (last accessed 26 April 2021): https://digital.nhs.uk/ data-and-information/publications/ci-hub/summary-hospital-levelmortality-indicator-shmi\#guidance-for-users;
}

describe patient circumstances and clinical characteristics. The inclusion of these variables is to adjust the observed outcome of success/failure to reflect all contributing factors.

How to estimate the personalised success rate?

Develop a model or adopt an existing one for the estimation of factors contributing to the chance of success.

One established model that could be used is the logit regression model adopted by the NHS England to estimate Summary Hospital-level Mortality Indicator (SHMI) ${ }^{13}$.

By regressing the patient-specific factors, other factors, and an intercept on the observed outcome (success vs. failure) for the entire sample, including all clinics, the estimated regression coefficients could reveal important evidence as to how each patient-specific factor contributes to the chance of success, forming the basis for understanding individual patient's chance of success.

How to compare the personalised success rate?

Take any IVF patient as an example for illustration purposes. This patient's circumstances are defined by a set of categorical variables as mentioned above (age, test results, infertility cause, treatment protocol, etc.).

\footnotetext{
13 The detailed specification of the logit model can be accessed here (last accessed 24 April 2021): https://digital.nhs.uk/data-and-infor mation/publications/ci-hub/summary-hospital-level-mortality-indic ator-shmi\#shmi-specification. The logit regression models is adopted by NHS England to estimate hospital-level expected mortality rates adjusted for risk, which is necessary for the calculation of SHMI that is comparable across hospitals.
} 
The expected success rate (with estimated confidence intervals, i.e. upper and lower control limits ${ }^{14}$ ) for the patient in this example can be calculated based on the multiplication of the estimated regression coefficients in the above model and the observed circumstances, defined by all relevant categorical variables above, specifically relating to this patient.

Compare (1) the observed success among all patients who fall into the same categories as this example patient in a given clinic with (2) the above expected success rate (with 95\% confidence interval estimates) to give the following result:

"No different than the expected rate" if the 95\% confidence interval estimate surrounding the above expected success rate includes the clinic's observed rate

"Worse than the expected rate" if the entire 95\% confidence interval estimate surrounding the expected success rate is higher than the clinic's observed rate.

"Better than the expected rate" if the entire $95 \%$ interval estimate surrounding the expected rate is lower than the clinic's observed rate.

"The number of cases is too small to reliably tell how well the clinic is performing."

Patients should be made aware of the limitations of the expected success rate. For instance, the set of variables are unlikely to completely describe a patient's circumstance. The more variables we include, the less precise the estimates are. Any estimation can only be accurate at the level of population. These limitations should be put to any given patient.

Example 2. An illustrative example of how success rates can be adjusted for patient mix, and made comparable across clinics

How to adjust success rates for patient mix $^{15}$ ?

Observed success at a clinic: This can be obtained by counting the number of successes among all patients in the sample at a clinic.

Expected success at a clinic: Regression coefficients (estimated using the same model in Example 1) multiplied by observed patient characteristics plus the intercept can be transformed and summed over all patients from the clinic to obtain expected success.

\footnotetext{
14 There are well-established methods to compute confidence intervals for the predicted outcomes at the specific values of the independent variables for regression models relating to categorical outcomes such as logit regressions (see, for instance, the different methods of such computation using Stata proposed by $\mathrm{Xu}$ and Long [58].

15 The approach illustrated in this example is very similar to the approach adopted by NHS to estimate and report SHMI as a measure of hospital care quality indicator. It gives the outcomes of hospitallevel mortality rates (for different diagnoses) adjusted for risk factors and is comparable across different hospitals.
}

Adjusted success rate at a clinic: The ratio of observed success at a given clinic over 'expected' success (calculated above). It conceptually allows for a comparison of a particular clinic's performance given its case mix to expect the clinic's performance with the same case mix. Together with this point estimate, upper and lower control limits can be reported.

How to compare and report success rates across clinics?

Regulators can assign a clinic to a performance category by comparing each clinic's observed success rate to the expected rate. For instance:

"No different than the expected rate" if the $95 \%$ confidence interval estimate surrounding the clinic's expected success rate includes the observed rate

"Worse than the expected rate" if the entire 95\% confidence interval estimate surrounding the clinic's expected success rate is higher than the observed rate

"Better than the expected rate" if the entire 95\% interval estimate surrounding the clinic's expected rate is lower than the observed rate

"The number of cases is too small to reliably tell how well the clinic is performing."

Example 3. An illustrative example of how the quality of evidence on reported success rates can be assessed.

\section{Regulators' role}

Setting the standards for data collection: For example, the sample and variables to be included.

Data validity check: For instance, comparing data over the years to check consistency.

Assessing the accuracy of algorithms used to analyse the data and compute the results: For example, crossed-checked by different data analysts.

Updating and refining the methods: Continually assessing the model and its validity given possible changes in the data over time, and allows for model refinements.

Patient engagement

The above information in Examples 1 and 2 should be disclosed at the stage when patients are doing research to choose clinics, so as to help to break down patient search barriers.

Patients should be given the opportunity to contribute to the above evidence disclosure process. Examples are:

- Format of the reported evidence: For example, a pilot can be used as a trial among patients to determine the most suitable format to compare success rates described in Examples 1 and 2 (e.g. an illustrative online predictor based on model estimates explained in Examples 1 and 2) and where such information should be reported (e.g. regulator website, clinic's website, or a specific online clinic comparison platform) 
- Patients (or the public) should be encouraged to provide feedback on data and methods or to share their own experience and observations (for instance, through an online platform monitored by the regulator) that allows regulators to reassess/refine the model and the accuracy of its prediction

\section{Declarations}

Funding Not applicable.

Conflict of interest Minyan Zhu declares she has no conflicts of interest.

Availability of data and material (data transparency) All data used in this article are available for public access and data sources are provided in the references section. No new data were generated by the author.

Open Access This article is licensed under a Creative Commons Attribution-NonCommercial 4.0 International License, which permits any non-commercial use, sharing, adaptation, distribution and reproduction in any medium or format, as long as you give appropriate credit to the original author(s) and the source, provide a link to the Creative Commons licence, and indicate if changes were made. The images or other third party material in this article are included in the article's Creative Commons licence, unless indicated otherwise in a credit line to the material. If material is not included in the article's Creative Commons licence and your intended use is not permitted by statutory regulation or exceeds the permitted use, you will need to obtain permission directly from the copyright holder. To view a copy of this licence, visit http://creativecommons.org/licenses/by-nc/4.0/.

\section{References}

1. Djulbegovic B, Guyatt GH. Progress in evidence-based medicine: a quarter century on. Lancet. 2017;390(10092):415-23. https:// doi.org/10.1016/S0140-6736(16)31592-6.

2. Djulbegovic B, Bennett CL, Guyatt G. A unifying framework for improving health care. J Eval Clin Pract. 2019;25(3):358-62.

3. Djulbegovic B, Bennett CL, Guyatt G. Failure to place evidence at the center of quality improvement remains a major barrier for advances in quality improvement. J Eval Clin Pract. 2019;25(3):369-72.

4. Mondoux S, Shojania KG. Evidence-based medicine: a cornerstone for clinical care but not for quality improvement. J Eval Clin Pract. 2019;25(3):363-8.

5. Heneghan C, Spencer EA, Bobrovitz N, Collins DRJ, Nunan D, Plüddemann A, et al. Lack of evidence for interventions offered in UK fertility centres. BMJ. 2016;355: i6295. https://doi.org/10. 1136/bmj.i6295.

6. The Competition and Markets Authority (CMA). Draft guidance for fertility clinics on consumer law: helping fertility clinics comply with their consumer law obligations. 2020. https://www.gov. uk/cma-cases/self-funded-ivf-consumer-law-guidance. Accessed 18 Jan 2021.

7. Lambert H. Accounting for EBM: notions of evidence in medicine. Soc Sci Med. 2006;62:2633-45.

8. Akerlof GA. The market for lemons: quality, uncertainty and the market mechanism. Q J Econ. 1970;8(3):408-500.
9. Arrow KJ. Uncertainty and the welfare economics of medical care. Am Econ Rev. 1963;53(1):941-73.

10. Darby MR, Karni E. Free competition and the optimal amount of fraud. J Law Econ. 1973;16(1):67-88.

11. Roe B, Sheldon I. Credence good labeling: the efficiency and distributional implications of several policy approaches. Am J Agron Econ. 2007;89(4):1020-33.

12. Dulleck U, Kerschbamer R. On doctors, mechanics, and computer specialists: the economics of credence goods. J Econ Lit. 2006;44(1):5-42.

13. Balafoutas L, Kerschbamer R. Credence goods in the literature: what the past fifteen years have taught us about fraud, incentives, and the role of institutions. J Behav Exp Finance. 2020;2020(26):100-285.

14. Klein B, Leffler K. The role of market forces in assuring contractual performance. J Polit Econ. 1981;89:615-41.

15. Shapiro C. Premiums for high quality products as returns to reputations. Q J Econ. 1983;98:659-79.

16. Balafoutas L, Fornwagner H, Kerschbamer R, Sutter M, Tverdostup M. Diagnostic uncertainty and insurance in credence goods markets. Mimeo, Department of Public Finance, University of Innsbruck; 2020.

17. Grossman SJ, Hart OD. disclosure laws and takeover. J Finance. 1980;35(2):323-34.

18. Grossman SJ. The informational role of warranties and private disclosure about product quality. J Law Econ. 1981;24(3):461-83.

19. Milgrom PR. Good news and bad news: representation theorems and applications. Bell J Econ. 1981;12(2):380-91.

20. Viscusi WK. A note on 'lemons' markets with quality certification. Bell J Econ. 1978;9(1):277-9.

21. Fishman MJ, Hagerty KM. Mandatory versus voluntary disclosure in markets with informed and uninformed customers. J Law Econ Organ. 2003;19(1):45-63.

22. Hirshleifer D, Lim S, Teoh SH. Disclosure to an Audience with Limited Attention. Ohio State University Charles A. Dice Center for Research in Financial Economics Working Paper 21; 2004.

23. Levin D, Peck J, Ye L. Quality disclosure and competition. J Ind Econ. 2009;57(1):167-96.

24. Jin GZ. Competition and disclosure incentives: an empirical study of HMOs. RAND J Econ. 2005;36(1):93-112.

25. Jansen J. A note on quality disclosure and competition. J Ind Econ. 2017;65(4):833-41.

26. Board O. Competition and disclosure. J Ind Econ. 2009;57(1):197-213.

27. The Competition and Markets Authority (CMA). Self-funded IVF Research. Prepared by Research Works Limited. 2020. https:// www.gov.uk/cma-cases/self-funded-ivf-consumer-law-guidance. Accessed 18 Jan 2021.

28. The Human Fertilisation and Embryology Authority (HFEA). National Fertility Patient Survey 2018. 2020. https://www.hfea. gov.uk/about-us/news-and-press-releases/2018-news-and-pressreleases/our-national-patient-survey-results/. Accessed $23 \mathrm{Apr}$ 2021.

29. The Human Fertilisation and Embryology Authority (HFEA). Fertility treatment 2018: trends and figures. HFEA; 2020

30. LaingBuisson. IVF-a dynamic, innovative and growing market in the UK. Press Release. 2018. https://www.laingbuisson.com/ blog/ivf-a-dynamic-innovative-and-growing-market-in-the-uk/. Accessed 14 Jun 2021.

31. The Human Fertilisation and Embryology Authority (HFEA). Revised code of conduct 2019. HFEA; 2019.

32. Bundorf KM, Chun N, Goda GS, Kessler DP. Do markets respond to quality information? The case of fertility clinics. J Health Econ. 2009;28(3):718-27.

33. Milgrom PR, Roberts J. Price and advertising signals of product quality. J Polit Econ. 1986;94(4):796-821. 
34. Daughety AF, Reinganum JF. Competition and confidentiality: signalling quality in a duopoly when there is universal private information. Games Econ Behav. 2007;58(1):94-120.

35. Jovanovic B. Truthful disclosure of information. Bell J Econ. 1982;13(1):36-44.

36. Matthews S, Postlewaite A. Quality testing and disclosure. RAND J Econ. 1985;16(3):328-40.

37. Shavell S. Acquisition and disclosure of information prior to sale. RAND J Econ. 1994;25(1):20-36.

38. Mathios AD. The impact of mandatory disclosure laws on product choices: an analysis of the salad dressing market. J Law Econ. 2000;43(2):651-77.

39. Bennear LS, Olmstead SM. The impacts of the "right to know": information disclosure and the violation of drinking water standards. J Environ Econ Manag. 2008;56(2):117-30.

40. Wedig GJ, Tai-Seale M. The effect of report cards on consumer choice in the health insurance market. J Health Econ. 2002;21:1031-48.

41. Jin GZ, Sorensen AT. Information and consumer choice: the value of publicized health plan ratings. J Health Econ. 2006;25(2):248-75.

42. Leemore D, Dranove D. Do report cards tell consumers anything they don't already know? The case of medicare HMOs. RAND J Econ. 2008;39(3):790-821.

43. Dranove D, Satterthwaite MA. Monopolistic competition when price and quality are imperfectly observable. Rand J Econ. 1992;23(4):518-34.

44. Dranove D, Jin GZ. Quality disclosure and certification: theory and practice. J Econ Lit. 2010;48(4):935-63.

45. Dranove D, Kessler D, McClellan M, Satterthwaite M. Is more information better? The effects of 'report cards' on health care providers. J Polit Econ. 2003;111(3):555-88.

46. GRADE Working Group. Grading quality of evidence and strength of recommendations. BMJ. 2004;328(7454):1490-4.

47. Busse R, Klazinga N, Panteli D, Quentin W. Improving healthcare quality in Europe: characteristics, effectiveness and implementation of different strategies. The European Observatory on Health Systems and Policies and OECD; 2019.
48. Fong Y, Liu T, Wright DJ. On the role of verifiability and commitment in credence goods markets. Int J Ind Organ. 2014;37:118-29.

49. Dulleck U, Kerschbamer R, Sutter M. The economics of credence goods: an experiment on the role of liability, verifiability, reputation, and competition. Am Econ Rev. 2011;101:530-59.

50. Hennig-Schmidt H, Selten R, Wiesen D. How payment systems affect physicians' provision behavior-an experimental investigation. J Health Econ. 2011;30:933-49.

51. Hennig-Schmidt H, Wiesen D. Other-regarding behavior and motivation in health care provision: an experiment with medical and non-medical students. Soc Sci Med. 2014;108:156-65.

52. Beck A, Kerschbamer R, Qiu J, Sutter M. Shaping beliefs in experimental markets for expert services: guilt aversion and the impact of promises and money-burning options. Games Econ Behav. 2013;81:145-64.

53. Godager G, Wiesen D. Profit or patients' health benefit? Exploring the heterogeneity in physician altruism. J Health Econ. 2013;32:1105-16.

54. Delfgaauw J. Dedicated doctors: public and private provision of health care with altruistic physicians. Tinbergen Institute Discussion Paper No. 07010/1. Amsterdam and Rotterdam: Tinbergen Institute; 2007.

55. Kruse FM, Stadhouders NW, Adang EM, Groenewoud S. Do private hospitals outperform public hospitals regarding efficiency, accessibility, and quality of care in the European Union? A literature review. Int J Health Plann Manag. 2018;33:434-53. https:// doi.org/10.1002/hpm.2502.

56. Kerschbamer R, Sutter M, Dulleck U. How social preferences shape incentives in (experimental) markets for credence goods. Econ J. 2017;127(600):393-416.

57. Liu T. Credence goods markets with conscientious and selfish experts. Int Econ Rev. 2011;52:227-44.

58. Xu J, Long JS. Confidence intervals for predicted outcomes in regression models for categorical outcomes. Stand Genom Sci. 2005;5(4):537-59. 